\title{
EL ITINERARIO DE UNA UNIVERSIDAD CATÓLICA
}

\section{Benedicto XVI \\ Papa Emérito}

Resumen: En este discurso, Benedicto XVI, con la sapiencia que lo caracteriza, delinea el itinerario que sigue el trabajo de una Universidad católica. Para ello, en primer lugar, recuerda las características de una comunidad católica académica, propuestas por su antecesor san Juan Pablo II. Luego, el Papa Emérito se concentra en la investigación, aquella que sostiene una confrontación estimulante entre fe y razón. Afirma el Papa que, a la luz de la revelación de Cristo, es posible conjugar fe y ciencia, e invita a los "pescadores de hombres" — es decir, personas de conciencia y bien preparadas - a poner su competencia profesional al servicio del bien. En conclusión, la Universidad católica está destinada a la gloria de Dios, y a la promoción espiritual y material de la humanidad.

Palabras clave: Universidad católica, universidad, investigación científica, competencia profesional, comunidad académica, Juan Pablo II, fe, razón.

\section{THE ITINERARY OF A CATHOLIC UNIVERSITY}

AвSTRACT: In this speech, Benedict XVI, with the wisdom that characterizes it, delineates the itinerary that follows the work of a Catholic University. For this, it recalls the characteristics of an academic Catholic community, proposed by his predecessor Saint John Paul II. Then, Pope Emeritus concentrates on research, the one that sustains a stimulating confrontation between faith and 
reason. The Pope affirms that in light of the revelation of Christ, it is possible to combine faith and science, and invites the "fishers of men" — that is, people of conscience and well prepared - to put their professional competence at the service of good. In conclusion, the Catholic University is destined for the glory of God, and the spiritual and material promotion of humanity. KeYwords: Catholic University, university, scientific investigation, professional competence, academic community, John Paul II, faith, reason.

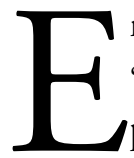

n efecto, si toda universidad tiene como misión fundamental "la constante búsqueda de la verdad mediante la investigación, la conservación y la comunicación del saber para el bien de la sociedad" (Ex corde Ecclesiae [ECE], 30), una comunidad académica católica se distingue por la inspiración cristiana de las personas y de la comunidad misma, por la luz de la fe que ilumina la reflexión, por la fidelidad al mensaje cristiano tal como lo presenta la Iglesia y por el compromiso institucional al servicio del pueblo de Dios (ECE, 13).

Por eso, la Universidad católica es un gran laboratorio en el que, según las diversas disciplinas, se elaboran itinerarios siempre nuevos de investigación en una confrontación estimulante entre fe y razón, orientada a recuperar la síntesis armoniosa lograda por santo Tomás de Aquino y por los otros grandes del pensamiento cristiano, una síntesis contestada, lamentablemente, por importantes corrientes de la filosofía moderna. La consecuencia de esta contestación ha sido que, como criterio de racionalidad, se ha afirmado de modo cada vez más exclusivo el de la demostración mediante el experimento. Así, las cuestiones fundamentales del hombre — como vivir y morir- quedan excluidas del ámbito de la racionalidad, y se dejan a la esfera de la subjetividad. 
Como consecuencia, al final desaparece la cuestión que dio origen a la universidad — la cuestión de la verdad y del bien-, siendo sustituida por la cuestión de la factibilidad. Por tanto, el gran desafío de las universidades católicas consiste en hacer ciencia en el horizonte de una racionalidad verdadera, diversa de la que hoy domina ampliamente, según una razón abierta a la cuestión de la verdad y a los grandes valores inscritos en el ser mismo y, por consiguiente, abierta a lo trascendente, a Dios.

Ahora bien, sabemos que esto es posible precisamente a la luz de la revelación de Cristo, que unió en sí a Dios y al hombre, la eternidad y el tiempo, el espíritu y la materia. "En el principio existía el Verbo el Logos, la razón creadora-. (...) Y el Verbo se hizo carne" (Jn 1,1; 14). El Logos divino, la razón eterna, está en el origen del universo, y en Cristo se unió una vez para siempre a la humanidad, al mundo y a la historia. A la luz de esta verdad capital de fe y, al mismo tiempo, de razón, es posible nuevamente, en el tercer milenio, conjugar fe y ciencia.

Sobre esta base se desarrolla el trabajo diario de una universidad católica. ¿No es una aventura que entusiasma? Sí, lo es porque, moviéndose dentro de este horizonte de sentido, se descubre la unidad intrínseca que existe entre las diversas ramas del saber: la teología, la filosofía, la medicina, la economía, cada disciplina, incluidas las tecnologías más especializadas, porque todo está unido. Elegir la Universidad católica significa elegir este planteamiento que, a pesar de sus inevitables límites históricos, caracteriza la cultura de Europa, a cuya formación las universidades nacidas históricamente "ex corde Ecclesiae" han dado efectivamente una aportación fundamental.

Por tanto, queridos amigos, con renovado amor a la verdad y al hombre echad las redes mar adentro, en la alta mar del saber, confiando en 
la palabra de Cristo, aun cuando sintáis el cansancio y la desilusión de no haber "pescado" nada. En el vasto mar de la cultura Cristo necesita siempre "pescadores de hombres", es decir, personas de conciencia y bien preparadas, que pongan su competencia profesional al servicio del bien, es decir, en último término, del reino de Dios.

También el trabajo de investigación dentro de la universidad, si se realiza desde una perspectiva de fe, ya forma parte de este servicio al Reino y al hombre. Pienso en toda la investigación que se lleva a cabo en los múltiples institutos de la Universidad católica: está destinada a la gloria de Dios y a la promoción espiritual y material de la humanidad.

Fragmento del discurso pronunciado en ocasión de la apertura del 85. ${ }^{\circ}$ Curso Académico en la Universidad Católica del Sagrado Corazón (25 de noviembre de 2005) 